\title{
LA INDEPENDENCIA (COMO ATRIBUTO) DE LOS ORGANISMOS REGULADORES SUDAMERICANOS: ESPECIAL ÉNFASIS EN EL CASO PERUANO'
}

\author{
The independence (as attribute) of the South \\ American regulatory organizations: \\ Special emphasis in the Peruvian case
}

\author{
MIRKO A. MALDONADO MELÉNDEZ \\ Universidad del País Vasco/Euskal Herriko Unibertsitatea \\ mr.mamm3@gmail.com
}

Cómo citar/Citation

Maldonado Meléndez, M. A. (2019).

La independencia (como atributo) de los organismos reguladores

sudamericanos: especial énfasis en el caso peruano.

Revista de Estudios Políticos, 186, 201-238.

doi: https://doi.org/10.18042/cepc/rep.186.07

\section{Resumen}

El presente artículo tiene como objetivo determinar el nivel de independencia de los organismos reguladores respecto del poder político y los diferentes órganos de la administración gubernamental, en especial en los países sudamericanos y en particular el caso peruano. Se analiza la legislación extranjera en sus dos sistemas tradicionales (anglosajón y europeo continental) para, a través de un enfoque cualitativo, evaluar la realidad en el caso peruano y proponer alternativas de mejora respecto de la actual legislación sobre la materia, revisando las distintas clases de independencia de los organismos reguladores sudamericanos, sus competencias y potestades, estatutos jurídicos, organización, parámetros, similitudes y diferencias, estableciendo en qué medida los controles estatales inciden en su organización, funcionamiento y

\footnotetext{
El presente trabajo es fruto del desarrollo reflexivo de lo que en su momento fue el capítulo III de mi tesis doctoral denominada Los organismos reguladores de los servicios de red del Perú (en comparación con la $C N M C$ ), dirigida por el catedrático de Derecho Constitucional de la Universidad del País Vasco, Eduardo Vírgala Foruria, y defendida en Leioa en octubre de 2016.
} 
toma de decisiones, arribando en la discusión de resultados sobre la independencia en cuestión, con propuestas de cambios legislativos para lograr una menor injerencia del poder político y asegurar una mayor imparcialidad en sus actuaciones.

\title{
Palabras claves
}

Competencia; independencia; organismos reguladores; reforma del Estado; regulación; control; potestades.

\begin{abstract}
The objective of this article is to determine the level of independence of the regulatory bodies with respect to the political power and the different organs of the government administration, especially in the South American countries, particularly the Peruvian case. The author analyzes the foreign legislation in its two traditional systems (Anglo-Saxon and continental European) to, through a qualitative approach, analyze the reality in the Peruvian case and propose alternatives for improvement with respect to the current legislation on the subject, reviewing the different kinds of independence of the South American Regulatory Bodies, their powers and attributes, legal statutes, organization, parameters, similarities and differences, establishing the extent to which state controls affect their organization, operation and decision making, arriving at the discussion of results on the independence in question, with proposals for legislative changes to achieve a lesser interference of political power and ensure greater impartiality in their actions.
\end{abstract}

\section{Keywords}

Competition; independence; reform of the State; regulatory bodies; regulation; control; powers. 


\section{SUMARIO}

I. INTRODUCCIÓN. II. LA INDEPENDENCIA DE LOS ORGANISMOS REGULADORES SUDAMERICANOS: ÉNFASIS EN EL CASO PERUANO: 1. Clases de independencia de los Organismos reguladores sudamericanos: 1.1. Independencia frente al poder político. 1.2. Independencia institucional. 1.3. Independencia funcional. 1.4. Independencia personal, subjetiva. 1.5. Independencia en su organización interna. 1.6. Independencia económica y financiera. 1.7. Presupuesto dependiente. 1.8. Presupuesto independiente. 1.9. Administración de recursos financieros. 1.10. Administración de recursos humanos. 1.11. Independencia frente al poder económico. 2. Competencia sobre el sector a regular. 3. Función y potestades preestablecidas. III. ESTATUTO JURÍDICO: LA ORGANIZACIÓN DE LOS ORGANISMOS REGULADORES. IV. PARÁMETROS PARA SER CONSIDERADO COMO REGULADOR Y CARACTERÍSTICAS COMUNES ENTRE LOS ORGANISMOS REGULADORES SUDAMERICANOS. V. SIMILITUDES ENTRE LOS ORGANISMOS REGULADORES. VI. CONTROLES SOBRE LOS ORGANISMOS REGULADORES SUDAMERICANOS: 1. El control parlamentario: 1.1. Procedimientos de investigación por parte del Parlamento. 1.2. Solicitud de información al organismo regulador. 2. Control por parte de la opinión pública: 2.1. Control ciudadano. 2.2. Control por parte de los medios de prensa. 3. Control judicial: 3.1. Impugnación en sede contencioso-administrativa. 3.2. Garantías constitucionales. 4. Control por parte del Gobierno. VII. CONCLUSIONES. BIBLIOGRAFía.

\section{INTRODUCCIÓN}

El origen histórico de las denominadas autoridades reguladoras de los servicios de red es sumamente claro. La línea de referencia nos lleva al sistema político estadounidense, que planteó la necesidad de crear agencias al servicio del Congreso que no estén bajo el control de la mayoría política o de quien ejerza el poder de turno ${ }^{2}$.

La estructura del aparato estatal estadounidense ha permitido la creación de dicho tipo de agencias que realizan funciones administrativas, sin estar bajo la dirección del Poder Ejecutivo, de tal forma que la diversidad de potestades

2 Sobre el tema, Eduardo Vírgala Foruria ha desarrollado in extenso el estudio de estos sistemas, tal como se aprecia en sus obras (Vírgala, 2004: 147-153, 2014: 172-174). Del mismo modo, véase Garrido (2002: 403-407) y Martí (2006: 99-102). 
que estas ejercen se puedan controlar y justificar de una manera más independiente. La creación de agencias gubernamentales de regulación dentro de la Administración pública estadounidense corresponden a una particular concepción de su sistema político, que considera como parte de sus políticas públicas la no injerencia del Ejecutivo en la composición, estructura y toma de decisiones de dichas agencias, las que se encuentran al servicio del Congreso de EE. UU., excluyendo el control del Gobierno central o de sus administraciones.

A diferencia del anterior, en los sistemas inspirados en el modelo europeo continental la Administración central está bajo el mando del Poder Ejecutivo, que es quien diseña las políticas a seguir por todas las administraciones públicas. Por tal razón, aun cuando se pretenda un cierto grado de independencia entre el Poder Ejecutivo y los reguladores, este siempre será relativo y atenuado en tanto dichas Administraciones públicas deban cumplir con una política sujeta por decisiones del Gobierno.

En esta línea de independencia del poder central, surge en España en el año 2013 la Comisión Nacional de Mercado y la Competencia (CNMC) como una organización distinta y ajena al aparato estatal, con personería jurídica propia, que ha sido materia de estudio en cuanto a su modelo de implantación en España y la justificación de esta nueva organización regulatoria de los mercados y la competencia. Ello ha supuesto la previa extinción de varios entes reguladores españoles, así como también ha implicado una recomposición de sus funciones a partir de las áreas de influencia de los entes absorbidos y los departamentos ministeriales, lo que hasta el momento ha sido visto de manera favorable puesto que no solamente se unifican criterios y se fortalece una única institución que supervise el correcto funcionamiento de la competencia, sino que en particular su modo de composición evidencia un cierto margen de independencia del Poder Ejecutivo, lo que favorece una menor injerencia en la toma de decisiones.

Los organismos reguladores sudamericanos - como es el caso del Perúestán inspirados en el modelo derivado de esta última corriente (continental-mediterránea) alojándose dentro de la estructura dirigida por la Administración central y, por tanto, no pueden desconocer al presidente de la República como máxima autoridad administrativa, no obstante que hoy en día existen mecanismos de control y de un marco legal de integridad de quienes ocupan los más altos cargos directivos, lo que hace indispensable el ejercicio de una estricta supervisión de la sociedad civil (bajo el modelo de juntas de usuarios).

En ese orden de idas, la independencia con que funcionan los organismos reguladores en los sistemas estadounidense, mediterráneo y sudamericano debiera ser entendida como el atributo a favor de la entidad para su 
manejo aséptico en el sector para el cual han sido creados, de modo que se encuentre alejado tanto del poder de turno (partido de gobierno) como de los operadores dominantes en el mercado, e incluso del propio presidente de la República, y a su vez del excesivo control que el Parlamento puede tener sobre la actividad regulatoria.

De cara a una mayor independencia en el sector donde operan los organismos reguladores, así como de una mayor credibilidad en el mercado y frente a la ciudadanía, lo que consecuentemente se materialice una verdadera eficacia en su actividad regulatoria, se hace necesario que el organismo cuente con mecanismos de fiscalización y de transparencia en la rendición de sus actos que muestren a los usuarios y a la comunidad que los métodos establecidos bajo tales parámetros de actuación cumplen a cabalidad con su cometido. En síntesis, una buena administración regulatoria que tenga presentes las necesidades colectivas de sus ciudadanos y cuya actuación administrativa reglada se encuentre plenamente sometida a la ley y al derecho.

En lo que respecta a la frágil independencia, es inevitable mencionar la influencia del poder político central, no solamente porque la convocatoria, selección y designación de los miembros de los directorios de tales entes se realiza muchas veces a propuesta del Poder Ejecutivo, sino que se permite que funcionarios de cierto órgano regulador sectorial, al culminar su periodo máximo de designación, se postulen a otro ente similar, generándose una especie de élite de funcionarios que de manera casi permanente rotan de uno a otro organismo regulador, produciéndose una concentración de poder en manos de unos pocos funcionarios.

\section{LA INDEPENDENCIA DE LOS ORGANISMOS REGULADORES SUDAMERICANOS: ÉNFASIS EN EL CASO PERUANO}

Los organismos reguladores sudamericanos están dentro de la organización dirigida por la Administración central y, por tanto, no pueden desconocer al presidente de la República como máxima autoridad administrativa. En este sentido, su independencia se verá atenuada; sin embargo, ello no quiere decir que el Ejecutivo tendrá control excesivo sobre los reguladores, puesto que sí se prevén ciertos mecanismos que aporten a un ejercicio autónomo de sus funciones y a una organización protegida de la injerencia de intereses políticos, sobre todo de los de turno, así como de empresas particulares (empresas operadoras); su independencia relativa puede ser suficiente para cumplir con su propósito de gestores indirectos de servicios públicos, vigilantes de las fallas de mercado y garantes de la defensa de los derechos fundamentales de los 
administrados y forma parte de un sistema jurídico-político llamado Estado de derecho (Betancor, 2010:344) .

\section{CLASES DE INDEPENDENCIA DE LOS ORGANISMOS REGULADORES SUDAMERICANOS}

\subsection{Independencia frente al poder político}

Los organismos reguladores sudamericanos se encuentran dentro de la estructura orgánica de los correspondientes poderes ejecutivos; por tanto, como se señalaba, su independencia del Gobierno será relativa y no absoluta. Sin embargo, se busca mediante parámetros estratégicos que la organización y las funciones de estos estén correctamente establecidas, de modo que puedan cumplir su propósito sin injerencia de los poderes de turno. Aun así, debemos tener en cuenta la especial característica que diferencia a los organismos que aquí estudiamos con respecto a las agencias independientes anglosajonas en las cuales se inspiraron.

Los sectores sobre los cuales actúan los organismos reguladores en diversos países diseñados bajo el modelo europeo continental —a diferencia del modelo anglosajón de tipo unitario- comparten la misma estructura bicéfala (Hernández, 2009:177). Bajo este diseño, en el interior de los organismos reguladores sudamericanos existe un ministerio a cargo de un sector determinado que elabora las políticas públicas de manera específica, con un plan que cumplir y, por otro lado, el organismo regulador sectorial destinado a realizar la gestión indirecta del servicio específico. Ambas funciones deben armonizar, en tanto la actuación del aparato estatal debe ser coherente y buscar el beneficio del usuario del servicio en pos de garantizar los derechos fundamentales de los ciudadanos (Vírgala, 2014:166). Por esto, los reguladores no pueden desconocer lo trazado por los ministerios o secretarías a su cargo. Sin embargo,

3 Asimismo, es destacable el éxito y la proliferación que tuvo el modelo despolitizado de regulación económica en la UE, cuyo estudio a profundidad ha sido desarrollado y estudiado por diversos investigadores. Al respecto, se señala que: «[S]in embargo, más allá de las diatribas doctrinales y de la "falta de una cultura de independencia (principalmente de las administraciones públicas) y de rendición de cuentas (debido a un control parlamentario ineficaz y una intervención judicial muy débil)", la emergencia y consolidación de Administraciones independientes en el sector económico no sólo no generó conflicto jurídico-constitucional significativo sino que, por el contrario, dando continuidad a esta "moda", conoció un espectacular desarrollo en la primera década del siglo xxi extendiéndose a nuevos sectores económicos y a la gestión de tradicionales servicios públicos» (Rallo, 2014:199). 
estas últimas no pueden interferir en el buen desempeño de la actividad regulatoria. En tal sentido, el profesor alemán Schmidt-Assmann destaca el poco estudiado tópico de la autonomía de la Administración planificadora, sosteniendo que «los mandatos legales de planificación y la discrecionalidad de planeamiento son dos fenómenos que, como puso tempranamente de relieve la jurisprudencia, van típicamente unidas» ${ }^{4}$.

Por otro lado, no solo se busca una independencia del presidente de la República, sino también del excesivo control que el Parlamento puede tener sobre la actividad regulatoria, por lo que se debe empezar por el análisis de las leyes que regulan la organización y funciones del organismo regulador, al ser estas aprobadas en el Parlamento. La mayoría política puede ejercer una indebida manipulación de los organismos reguladores, ya sea haciendo deficiente su organización —no articulando una normatividad sistémica, por ejemplo, u obstaculizando su funcionamiento- o ya sea, por ejemplo, estableciendo de manera vaga las atribuciones y competencias que tienen. De esta manera, las empresas de los sectores podrían escapar de una adecuada regulación, lo que terminaría perjudicando al usuario o administrado.

En síntesis, los parámetros de independencia del poder público pueden asociarse en tres grupos: aquellos de incidencia organizativa; los que tienen incidencia funcional y, en función de la materialización de las dos primeras, los parámetros con incidencia económica o financiera; pero es pertinente dejar establecido que estos no se limitan a fortalecer la independencia respecto del poder público, sino que también son una principal barrera frente a la intromisión de los agentes económicos externos.

\subsection{Independencia institucional}

Como primer grupo de parámetros, establecemos aquellos que otorgan una adecuada estructura orgánica al organismo regulador mediante una normativa que ayude al establecimiento de un nivel apropiado de discrecionalidad en sus actividades, empezando por la básica composición de un organismo distanciado del excesivo control de la Administración central, pero «dentro del aparato estatal». Es decir, el primer paso para que un regulador empiece a tener independencia orgánica es su reconocimiento como persona jurídica de derecho público con un tratamiento diferenciado de los típicos organismos descentralizados. A este último tipo de independencia institucional también se le conoce como independencia legal.

4 Schmidt-Assmann (2003: 215). 
En este sentido, es preferible que el beneficio de la independencia del organismo sea creado mediante ley y no mediante un decreto de la Presidencia de la República, que puede terminar haciendo que el regulador se ancle dentro de la estructura de un ministerio, restándole autonomía ${ }^{5}$, entendida esta última como la potestad para autoorganizarse, de tal manera que el órgano director del regulador pueda emitir los instrumentos de gestión necesarios para adecuar su organización y funcionamiento a la actividad que estos realizan. Para que el organismo regulador tenga una independencia organizativa, pueden considerarse una serie de parámetros que, a pesar de no ser establecidos exhaustivamente, consideramos mínimos para su correcta organización (Vírgala, 2011a: 298-302).

La independencia orgánica o institucional se manifiesta de la siguiente manera $^{6}$ :

- Personalidad jurídica.

- Entidad de derecho público.

- Entidad que la ley la califique como independiente o que actúa independiente.

- Adscripción a un departamento ministerial.

\subsection{Independencia funcional}

En un segundo grupo de parámetros podemos establecer aquellos que buscan garantizar el ejercicio concreto de las funciones del regulador de forma independiente. Así, se debe alcanzar una independencia de la Administración central (el presidente y los ministros) con respecto a la existencia o no de una relación jerárquica del regulador con esta; y, por otro lado, el tipo de sujeción del regulador ante las normas, directrices o planes dictados por el Gobierno.

$5 \mathrm{Al}$ respecto, afirma Vírgala que «[... la independencia de las autoridades administrativas debe concretarse además de en su creación mediante ley formal para que el Gobierno no pueda modificar su estatuto jurídico, en tres condiciones sin las cuales no existe, de forma que la ausencia de alguna de ellas hace que la AAI dependa del Gobierno, no tenga una capacidad de actuación propia y no plantee por ello problema alguno de constitucionalidad al ser un órgano más de la Administración General del Estado.» (Vírgala, 2011a:297). Las tres condiciones que menciona el autor citado son el nombramiento, el cese y las incompatibilidades respecto al cargo de los miembros del órgano directivo del organismo regulador; estas serán desarrolladas aquí en los puntos referidos a la elección y la estabilidad de los mencionados funcionarios.

6 Betancor (2010: 362 y ss.). 
De esta manera, el organismo regulador será más independiente, en tanto su vinculación con el Gobierno sea más flexible y en lo posible, mínima. En resumidas cuentas, debe existir una prohibición expresa que impida que se le puedan impartir directivas, instrucciones u órdenes.

\subsection{Independencia personal, subjetiva}

Está directamente relacionada con el nombramiento por parte del Gobierno de personal de reconocida trayectoria y de reconocida cualificación profesional en los asuntos relacionados con las funciones del organismo regulador. A esto es necesario recalcar además que en este tipo de nombramiento en el caso peruano el Congreso debería ejercer la facultad de veto al candidato o postulante tal como sucede en el caso de la Comisión Nacional de los Mercados de la Competencia.

La independencia de los organismos reguladores peruanos es endeble por cuanto la influencia del poder político central se manifiesta en diferentes momentos vinculados a la selección de sus consejos directivos, que muchas veces se realiza a propuesta del Poder Ejecutivo, a lo que se añade el hecho de que funcionarios de cierto órgano regulador sectorial al culminar su periodo máximo de designación postulan a otro ente similar, generándose una especie de élite que de manera casi permanente rotan de uno a otro organismo regulador, produciéndose una concentración de poder en manos de unos pocos funcionarios.

Considerando lo dicho, respecto a la duración del mandato de los directores al frente de los organismos reguladores, lo ideal en el caso peruano es que debería ser más extenso (superior) que el del presidente de la República. Esto se traduciría en:

— Límite de renovación por única vez.

— Régimen tasado de incompatibilidades.

- Participación de los organismos reguladores en la remoción o separación del director.

- Intervención del Congreso de la República a través de la Comisión de la Defensa de Consumidor y organismos reguladores (vía veto) para su separación y remoción.

\subsection{Independencia en su organización interna}

Este tipo de independencia descansa en su organización compleja (es decir piramidal, mixta con una serie de órganos); también un órgano de control interno es quien ejerce funciones de fiscalización y supervisión de su 
organización interna, así como del tema patrimonial. Además, su estatuto de organización y funcionamiento debe estar aprobado por el propio regulador.

\subsection{Independencia económica y financiera}

Los organismos reguladores, para llevar a cabo sus actividades de manera independiente, no solo deben tener una organización autónoma en donde se prevean sus potestades exclusivas, sino que deben tener los recursos materiales y humanos necesarios para ejercerlas ${ }^{7}$. En este sentido es importante para tener una independencia funcional y una orgánica, en especial con respecto de la Administración central, que se contemple en la ley de creación de organismos reguladores la obligatoriedad de asignación de recursos para este, así como la autonomía para su autofinanciación (ingresos propios), acompañado de métodos que alejen la injerencia del Gobierno. Por lo que resumiendo esto se traduciría en:

- Presupuesto propio.

- Patrimonio propio e independiente.

- Ingresos propios.

\subsection{Presupuesto dependiente}

En el presupuesto del sector público para un determinado año fiscal se debe determinar el correspondiente pliego presupuestario para los organismos reguladores. Dicho presupuesto es comúnmente elaborado por el poder ejecutivo - mediante el ministerio encargado de las políticas económicas-. Para el caso peruano es el Ministerio de Economía y Finanzas (MEF), y luego

Sería necesario adicionar 200 millones de soles adicionales a los que ya contaba OSIPTEL antes de la renovación del Contrato de Concesión con Telefónica del Perú S. A. A. Ver entrevista con el expresidente de OSIPTEL, disponible en: http://bit. ly/32VoCzc y http://bit.ly/2BWkeEc. Finalmente, para el cumplimiento de las metas gubernamentales, en especial a los organismos reguladores, tenemos que para el caso de OSIPTEL se requiere supervisión de la cobertura móvil de 2500 localidades del país. Para el caso de OSITRAN, para el 2015 era necesario realizar 2500 supervisiones a las 31 concesiones de infraestructura, otras 33 supervisiones a 2 empresas del Estado: la Empresa Nacional de Puertos (ENAPU) y la Corporación Peruana de Aeropuertos (CORPAC), así como emitir 15 informes relacionados con fines tarifarios (fijaciones), revisiones tarifarias e informes de contabilidad regulatoria. Para el caso de SUNASS, se requiere resolver 21000 apelaciones ante reclamos de usuarios. Ver informe completo del MEF en el siguiente enlace: http://bit.ly/2BYEYuU. 
aprobado por el Parlamento. En este sentido, ambos poderes tienen la decisión final sobre los recursos económicos que tendrá un organismo regulador a su disposición.

Para atenuar dicho control indirecto, de quién elabora y quién aprueba el presupuesto sobre el regulador, es necesario que este, mediante su órgano directivo, tenga la facultad de, por lo menos, proponer el presupuesto que debería asignársele. Sin embargo, las fuentes de financiación del regulador pueden establecerse de tres maneras:

- Única dependiente: cuando la asignación presupuestaria que viene del tesoro público es la única de la que se sirve la entidad para funcionar ${ }^{8}$.

- Única independiente: cuando no se le asigna un presupuesto que viene del tesoro público, sino que la entidad depende solo de los recursos que esta misma recauda.

- Mixta: cuando se le asigna un presupuesto del tesoro público en función de lo recaudado independientemente, estableciendo dos fuentes de financiación?

Considero que, a efectos de contribuir con un ejercicio continuo de una adecuada regulación independiente, el regulador debe estar en condiciones de proponer a la entidad encargada de elaborar el presupuesto del sector público que se le asigne un determinado monto que varíe cada año en función de la recaudación del año anterior. Así, sea cuales fueren las condiciones en el mercado, el organismo regulador tiene una financiación segura del tesoro público. Por el contrario, dejar a la discrecionalidad de algún ministerio una única fuente de financiación para el organismo atenta totalmente contra su independencia. Basta ver el presupuesto de la Presidencia del Consejo de Ministros, donde se incluye el presupuesto institucional anual (PIA) que se asignó en 2015 a los reguladores de los servicios públicos ${ }^{10}$ :

8 Un claro ejemplo de lo que se afirma líneas arriba se encuentra en la Ley 30281, del Presupuesto General de la República para el año fiscal 2015, publicado en el Diario Oficial El Peruano, de 4 de diciembre de 2014. Ver las disposiciones complementarias finales y transitorias y anexos: http://bit.ly/2Py4LSH.

9 Un ejemplo de lo mencionado de este punto está en la Ley 30372, del Presupuesto del Sector Público para el ańo fiscal 2016, de 30 de noviembre de 2015.

10 Ver las actas del pleno del Congreso de la República en su vigésima sesión, celebrada el 27 de noviembre de 2014 y la presencia de la presidenta de la PCM, en el siguiente enlace: http://bit.ly/34kxS0h. Y en clara referencia a la presentación de la expresidenta del Consejo de Ministros, Ana Jara Velásquez, en la justificación de su pliego presupuestal sectorial 01-PCM, p.17 http://bit.ly/2BYEYuU. 
Tabla 1. Presupuesto institucional de los organismos reguladores

\begin{tabular}{lccc}
\hline \multicolumn{4}{c}{ Presupuesto Institucional de Apertura - Or. (PIA) } \\
\hline Pliegos Del Sector & $\mathbf{2 0 1 4}$ & $\mathbf{2 0 1 5}$ & Part $\mathbf{\% ~ 2 0 1 5}$ \\
\hline OSIPTEL & 79 & 96 & $5 \%$ \\
\hline OSINERGMIN & 321 & 328 & $18 \%$ \\
\hline OSITRAN & 43 & 67 & $4 \%$ \\
\hline SUNASS & 26 & 27 & $2 \%$ \\
\hline Total & $\mathbf{4 6 9}$ & $\mathbf{5 1 8}$ & \\
\hline
\end{tabular}

Fuente: elaboración propia.

Gráfico 1. Presupuesto institucional de apertura de los organismos reguladores
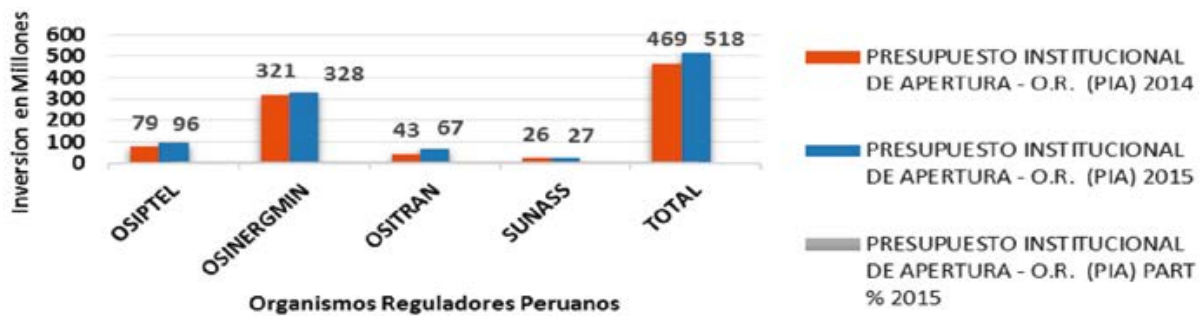

Fuente: elaboración propia.

\subsection{Presupuesto independiente}

Como los recursos financieros son tan determinantes para que el aparato administrativo del Organismo Regulador pueda funcionar, no solo la dependencia absoluta de la asignación presupuestaria del tesoro público puede ser un inconveniente respecto de su independencia, sino que estos además pueden resultar insuficientes, aunque se le otorgue lo máximo razonable. Por esto, es de extrema necesidad que el regulador tenga una vía de financiación autónoma, de modo que no dependa en ningún caso de las decisiones presupuestarias del poder ejecutivo o del legislativo.

Como ejemplo, en el Perú se ha utilizado con aparente éxito el «aporte por regulación», estableciéndose como única fuente de financiación para cada regulador. El aporte en este caso consiste en un uno por ciento «del valor de la facturación anual, deducido el impuesto general a las ventas y el impuesto de promoción municipal, de las empresas bajo su ámbito» ${ }^{11}$. De esta forma el

11 Ver art. 10 de la Ley 27332, Ley Marco de Organismos Reguladores de la Inversión Privada en los Servicios Públicos, que también establece: «Este aporte será fijado, en cada 
regulador se financia con el aporte de sus propios regulados, aunque ello sea una gran ventaja con respecto a utilizar solo los recursos del tesoro público para financiarse, se estaría dependiendo de los ciclos económicos en el mercado.

Por tanto, se insiste en la necesidad de un método mixto para la financiación de los reguladores, de tal manera que éstos puedan actuar, en cualquier caso. Aunque su sector se halle en una emergencia económica, éstos puedan tener recursos para actuar el siguiente año y seguir aplicando las medidas correspondientes. En caso contrario se pone en peligro que, por tratar de salvar a las empresas y los usuarios, se gaste mucho más de lo que se recaude, entrando en un déficit presupuestario del cual, el regulador tenga que ser auxiliado por la Administración central ${ }^{12}$.

\subsection{Administración de recursos financieros}

Aun cuando es de vital importancia establecer los mecanismos de obtención de recursos financieros, ello no sería suficiente si los organismos reguladores no tuvieran la autonomía financiera para hacer uso adecuado de éstos. Dicho de otro modo, luego de haberse obtenido los recursos financieros, es necesario que los instrumentos de gestión, así como las leyes de contrataciones y adquisiciones aplicables al regulador, le permitan gestionarse de manera independiente. Ello incluye la posibilidad de que, mediante directivas o leyes sobre la política económica del año fiscal, se imponga al regulador la adopción de medidas de austeridad o similares.

Por ello, es preciso que los organismos reguladores se encuentren facultados por ley para adoptar dichas medidas a fin de mejorar la calidad de la gestión pública, sin injerencia de ningún poder del Estado o entidad administrativa pública, dejando esta atribución en manos del propio regulador. Es decir, es el órgano directivo el que, en preservación de su independencia, debe aprobar las disposiciones de austeridad, disciplina y calidad del gasto público. De esta forma, el manejo de los recursos financieros debe realizarse de manera autónoma, pero observando las leyes que guíen dicha función para que no exista arbitrariedad alguna.

caso, mediante Decreto Supremo aprobado por el Consejo de Ministros, refrendado por el presidente del Consejo de Ministros y el Ministro de Economía y Finanzas».

12 Este ha sido el clamor de los presidentes de los organismos reguladores en su presentación en la Comisión de Defensa del Consumidor y Organismos Reguladores del Congreso de la República del Perú. Ver el punto 1 de la orden del día, de la Sexta sesión ordinaria, de 4 de noviembre de 2014: http://bit.ly/2pZPLm1. Adicionalmente, en medios de prensa escrita los Presidentes de los organismos reguladores declararon que se requiere más presupuesto para una mejor acción en el mercado: http://bit.ly/2otcZk0. 
En todo caso, es necesario prever en la ley de creación del organismo regulador, que su órgano directivo tenga las facultades necesarias para llevar a cabo una buena gestión del organismo, pudiendo contar — de ser necesario en su caso- con una gerencia general como órgano encargado de la autogestión administrativa, a manera de ejecutor de lo dispuesto por el órgano directivo. En este sentido, la división de tareas por una parte del último de estos órganos como órgano decisor y del primero, como órgano ejecutivo, establece una organización para el organismo regulador, sin dejar de lado, la facultad del órgano decisor de crear más gerencias si es necesario y justificado.

\subsection{Administración de recursos humanos}

$\mathrm{Al}$ igual que en el apartado anterior, se debe tener en cuenta primero la financiación del presupuesto que servirá, entre otras cosas, para la provisión de recursos humanos al organismo regulador, esto es, la fijación de los ingresos de su personal. En el mismo sentido, las disposiciones sobre austeridad y gestión limitada del gasto en el pago de las remuneraciones del personal deben ser aprobadas por el órgano directivo del organismo regulador. Además, se podría encargar de los procedimientos no decisorios a una gerencia de recursos humanos que trate todos los asuntos administrativos sobre el personal.

Pero existen más problemas. Si bien el mínimo de personal de confianza está determinado por ley, en muchos ordenamientos la legislación que regula el servicio civil puede estar dispersa, estableciendo varios regímenes aplicables. En este caso, aunque materialmente las contrataciones por regímenes especiales pueden ser beneficiosas a corto plazo, sin embargo, a largo plazo no se logran capacitar los técnicos de alto nivel que un organismo regulador necesita. Este tipo de entes necesita personal altamente capacitado para realizar estudios en materia económica, en la materia de sus correspondientes sectores y estudios que evalúen constantemente la necesidad de regulación.

Por ello, es necesario que la ley de contratación laboral para los organismos reguladores sea una ley general estable que permita la especialización técnica en el ascenso de su personal. Pero, sin dejar de lado que es necesario tener una mención especial en dicha ley o en la ley de creación del regulador, puesto que en muchos casos será necesario asignar remuneraciones que compitan con las que existen en el sector privado. Es necesario también que se establezcan excepciones que permitan al órgano directivo del regulador establecer el número de personal, categorías, rangos remunerativos, entre otros aspectos.

En conclusión, la independencia del regulador dependerá desde la fuente de financiación, pasando por la asignación presupuestaria y la administración de dicho recurso financiero, hasta el gasto más concreto de las remuneraciones del personal especializado. Solo así el regulador puede ser económicamente 
independiente, auto organizándolos en sus procedimientos para contratar especialistas y trabajadores que se identifiquen con la actividad regulatoria, siendo la fuerza de trabajo el corazón de toda gestión administrativa.

\subsection{Independencia frente al poder económico}

Este tipo de parámetros son establecidos al igual que los métodos para conseguir una independencia relativa, pero suficiente, en el ejercicio de las funciones del organismo regulador, pues también inciden en mantener alejada la influencia de las empresas que ostentan un poder preponderante en el mercado del sector a regular ${ }^{13}$. Debido a que dentro del mercado existen muchos intereses en juego, ello pone en peligro la independencia del regulador frente a los operadores regulados. Por ello, es necesario que los parámetros orgánicos y funcionales establecidos anteriormente se estructuren teniendo en cuenta la posibilidad de ejercer un control sobre las decisiones críticas del regulador.

Entonces, para que la independencia, la credibilidad y, consecuentemente, la eficacia de la actividad regulatoria se materialice es necesario que el organismo cuente con mecanismos de transparencia que muestren a los usuarios y a la comunidad que los métodos establecidos en esos parámetros cumplan su cometido. Un constante compromiso, no solo de las entidades públicas sino de las asociaciones de usuarios, previstas en el mismo ordenamiento del regulador. Además, los usuarios agrupados pueden solicitar con mayor ímpetu o presión los datos que deben estar bajo escrutinio público. De esta forma, la ley de creación del regulador debe prever facilidades para que una asociación o consejo de usuarios pueda representar a la comunidad usuaria del servicio regulado.

En conclusión, el trabajo del organismo regulador debe dejar una apertura a la planificación general de la Administración Central, una cooperación con agencias de la competencia que tengan funciones diferenciadas en el mismo sector, el respeto ético y colaborador por aportes de regulación por parte de los operadores económicos, y, finalmente, una coordinación de transparencia y rendición de cuentas con asociaciones de usuarios y consumidores (tal como se aprecia en la doctrina comparada europea, relativa a la transparencia y publicidad de las actuaciones de los reguladores). Todo ello, bajo los parámetros establecidos, puede otorgar un mínimo de independencia para que la actividad regulatoria tenga sentido, en caso contrario dicha función no tiene cabida en un Estado de derecho ${ }^{14}$.

13 Vírgala (2006: 168-172).

14 Vírgala (2011b: 113-115). 
Tabla 2. Ponderaciones para medir grado de independencia de los organismos reguladores ${ }^{15}$

\begin{tabular}{lll}
\hline & \multicolumn{2}{c}{ Calificación } \\
\cline { 2 - 3 } & Mala Regular Buena $\begin{array}{c}\text { Muy } \\
\text { Buena }\end{array}$ & PONDER \\
\hline Independencia subjetiva o personal & & \\
\hline Régimen estricto de incompatibilidades & 0.6 & \multirow{2}{*}{0.60} \\
\hline Independencia objetiva o funcional & 0.6 & \\
\hline Prohibición expresa que se le puedan & & \\
\hline impartir directivas, instrucciones u órdenes
\end{tabular}

\section{Independencia institucional}

Personalidad jurídica y plena capacidad pública y privada

\begin{tabular}{|c|c|c|c|}
\hline Entidad de derecho público & & 0.3 & \multirow{4}{*}{0.42} \\
\hline $\begin{array}{l}\text { Entidad que la ley expresamente califica } \\
\text { como independiente }\end{array}$ & & 0.6 & \\
\hline $\begin{array}{l}\text { Entidad que la ley expresamente que } \\
\text { actúa con autonomía }\end{array}$ & & 0.6 & \\
\hline $\begin{array}{l}\text { Adscripción expresa a algún } \\
\text { departamento ministerial }\end{array}$ & \multicolumn{2}{|r|}{0.3} & \\
\hline \multicolumn{4}{|l|}{ Independencia organización interna } \\
\hline Organización compleja & & 0.3 & \multirow[b]{3}{*}{0.33} \\
\hline Órgano de control interno & 0.1 & & \\
\hline $\begin{array}{l}\text { Estatuto de organización y } \\
\text { funcionamiento aprobado por el propio } \\
\text { organismo }\end{array}$ & & 0.6 & \\
\hline \multicolumn{4}{|l|}{ Independencia económica-financiera } \\
\hline Patrimonio propio e independiente & & 0.6 & 0.60 \\
\hline
\end{tabular}

Fuente: elaboración propia.

15 El presente cuadro fue elaborado con la finalidad de poder medir la independencia de los orgnaismos reguladores, para lo cual se ha hecho uso de indicadores y ponderaciones ideales para poder medir los mismos, amparados en leyes, normas técnicas reguladoras en el país. 
Gráfico 2. Nivel de independencia de los organismos reguladores

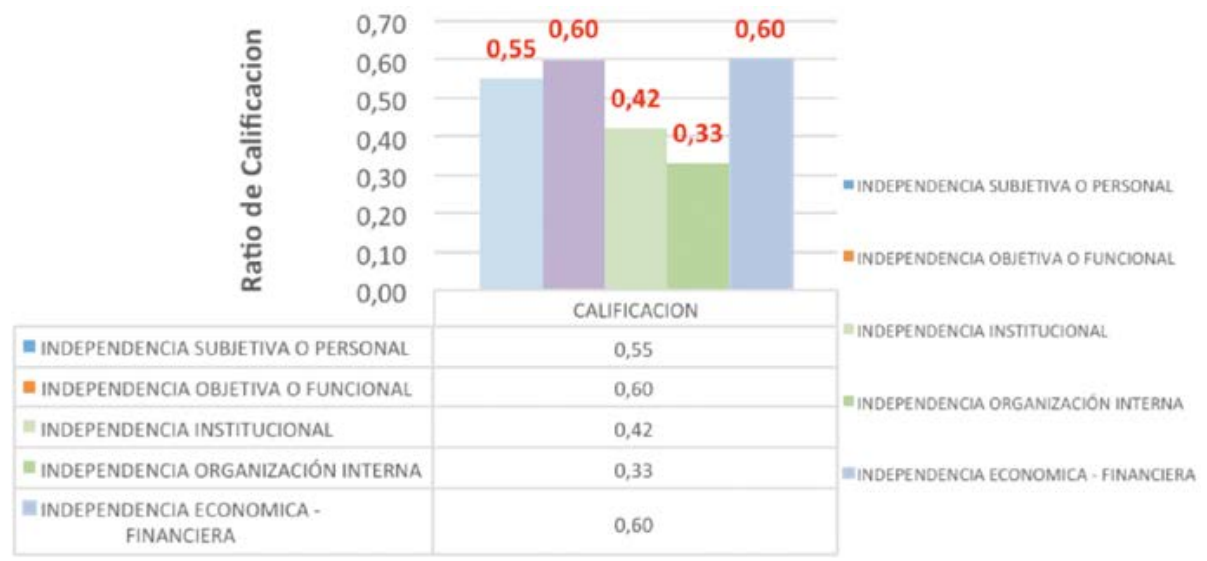

Fuente: elaboración propia.

\section{COMPETENCIA SOBRE EL SECTOR A REGULAR}

Como se ha establecido en un apartado precedente, el sistema europeo ha sido «imitado», en parte, por los sistemas sudamericanos. Tiene su incidencia en el control bicéfalo que tiene la Administración pública sobre el sector regulado. Es decir, por un lado, el Gobierno tiene competencias sobre el sector y por otro, también las tiene el organismo regulador correspondiente; por tanto, las competencias serán compartidas en ciertos puntos. En concreto, el Gobierno siempre se reservará la posibilidad de dictar las directrices y políticas públicas que deben ser tomadas siempre en cuenta por la Administración —en tanto organización unificada-, sobre el sector que debe ser regulado.

Esto no quiere decir que las funciones del regulador puedan ser ejercidas por el Gobierno; por el contrario, los métodos por los cuales las competencias exclusivas del regulador son fijadas serán determinantes para alcanzar una independencia relativa, pero suficiente para ejercer libremente sus actividades. Por ello, la ley de creación del regulador debe mantener una diferenciación de la competencia del regulador, dándole la exclusividad sobre ella en razón de la materia a tratar y estableciendo de manera estricta cómo será compartida con la Administración central u otras Administraciones públicas.

La Administración central debe limitarse a elaborar las políticas públicas generales en torno al sector regulado o de este como parte de un plan macro - por ejemplo—, de prestaciones de servicio público. El ministerio 
competente debe, además, establecer el lineamiento de programas asistenciales y de ayuda a la labor que realiza el regulador. Junto a esto, el organismo regulador, también debe tener la competencia para elaborar su plan operativo o plan de acción que se encuadre con el plan general de la Administración central, desarrollándose así un trabajo de cooperación y no de subordinación.

Los organismos de vigilancia del mercado y control de los requerimientos mínimos del comercio realizan actividades muchas veces en línea paralela con los reguladores; por ello, se debe evitar primero la duplicidad de funciones y luego, la interferencia de estas sobre decisiones ya tomadas por los reguladores, debido a que el regulador tiene potestades regulatorias que pueden reestructurar las reglas del mercado, mientras otros organismos que solo vigilan el cumplimiento de las reglas mínimas del mercado no pueden contravenir las normativas establecidas por los reguladores en sus reglamentos ni intervenir donde el regulador también tiene potestades de supervisión.

Con respecto a las competencias exclusivas del organismo regulador, estas deben ser determinadas según el principio de especialidad de la organización de la Administración pública ${ }^{16}$. Por tanto, se entiende que el organismo regulador es competente para realizar sus actividades sobre el sector y la excepción es la intervención de la Administración central en la ejecución de planes de gobierno y otras Administraciones públicas, en torno a la supervisión de los mercados en general. La regla general consiste en que el regulador es competente para intervenir en cualquier hecho de relevancia jurídica en el cual se dude de qué Administración pública deba actuar y cuándo existe alguna laguna jurídica.

\section{FUNCIÓN Y POTESTADES PREESTABLECIDAS}

La función regulatoria, como parte de la función administrativa, debe estar prevista expresamente en la ley de creación de los organismos reguladores, dejando de lado la vía constitucionalizada por la cual se sustenta el otorgamiento de dicha función con las consecuentes potestades. La naturaleza de este organismo se funda en que se le otorga una función normativa de regulación junto a potestades administrativas que forman en conjunto, una actividad administrativa sui géneris. Al respecto, el profesor Montero afirma que es necesario utilizar un concepto de actividad administrativa regulatoria o regulación mucho más restringido, criterio que comparto, proponiendo entender a la regulación «[...] como la actividad de la administración consistente en el

16 Cassagne (2010: 268-272). 
control continuo de un mercado mediante la imposición a sus operadores de obligaciones jurídicas proporcionales a propósitos de interés general objetivamente determinadas según la valoración que en un ámbito de extraordinaria discrecionalidad realiza la administración ${ }^{17}$. Considero necesario agregar que la actividad de regulación se puede manifestar mediante el dictado de reglamentos cuasi autónomos que reestructuren las reglas de juego de los mercados, haciéndolos más competitivos o eficientes, o mediante la aprobación o fijación de las tarifas de los servicios regulados; en todo caso, es necesario que la actividad regulatoria se componga de, por lo menos, la emisión de normas técnicas — sin naturaleza reglamentaria—, puesto que la actividad regulatoria variará en cada ordenamiento jurídico, siendo necesario que se especifiquen las potestades que se otorguen al regulador, que solo pueden ser desempeńadas por este, en tanto sus decisiones deben ser establecidas como definitivas en instancia administrativa. Las potestades establecidas para el organismo regulador pueden a su vez ser desarrolladas mediante un manual o un reglamento de organización y funciones por parte del propio regulador, junto a la potestad de regular las tarifas de la prestación de un servicio, por lo que podemos establecer tres potestades principales que, a grandes rasgos, se le atribuyen a la mayoría de los organismos reguladores en Sudamérica:

- Potestad normativa: consiste, primero, en la facultad del órgano director del organismo en dictar los reglamentos organizativos correspondientes para que este pueda llevar a cabo su función reguladora. En segundo lugar, se identifica una función normativa de regulación, por la cual el organismo, por medio de su órgano director, puede dictar reglamentos cuasi autónomos para la intervención económica indirecta en los sectores a regular.

- Potestad supervisora: consiste en la vigilancia y control de las reglas de juego del mercado y las reglas reestructuradas por el propio regulador para establecer un mercado competitivo o a servicio del usuario. En consecuencia, supone una potestad sancionadora en caso de que se infrinjan las reglas preestablecidas en las leyes o reglamentos que rigen el sector determinado.

— Potestad cuasi jurisdiccional ${ }^{18}$ : consiste en la resolución de conflictos que puedan sucederse entre empresas o entre estas y usuarios, mediante la cual se busca sancionar a una empresa infractora o decidir una incertidumbre jurídica.

17 Montero (2014a: 27).

18 Gordillo (2003: 12-13). 
En conclusión, el organismo regulador debe tener una fuerte capacidad de decisión sobre el sector que va a regular, teniendo como mínimo su potestad normativa y la de regular tarifas del servicio para ser considerado como tal, además de, si tiene las demás potestades descritas, poder coordinar con las demás Administraciones públicas para que no se lleve a cabo algún acto que ponga en duda la vigencia de las decisiones del regulador (Schmidt-Assmann, 2003: 220-221) ${ }^{19}$. En consecuencia, debe excluir cualquier directiva de la Administración que busque desconocer la legalidad de sus resoluciones y reglamentos que no pueden ser revisados por otra instancia administrativa alguna.

\section{ESTATUTO JURÍDICO: LA ORGANIZACIÓN DE LOS ORGANISMOS REGULADORES}

De conformidad con lo dispuesto en el inciso 6.1 del art. 6 de la Ley Marco de Organismos Reguladores en el Perú, como sucede en Espańa con la Comisión de los Mercados de la Competencia (CNMC), la legislación establece una estructura casi uniforme al igual que otros países sudamericanos, pues poseen un órgano de dirección, una presidencia del mismo que ejecuta los acuerdos adoptados de parte del colegiado, el cual está compuesto por un número impar de miembros, así como un órgano de control institucional.

Este estatuto jurídico (reglamento interno), es expedido por el mismo ente, lo que permite efectuar el control o supervisión de las actividades propias del regulador, así como su interacción con los sujetos, fundamentalmente privados, que actúan en sectores económicos o mercados en el que esté presente un interés público superior. El mencionado Estatuto coadyuva al buen funcionamiento de los mercados y constituye una garantía de los derechos de los ciudadanos a su acceso universal.

19 Siguiendo al profesor alemán, hay que tener en cuenta la evolución de la teoría de la discrecionalidad administrativa, entendiéndose ésta como «una facultad específica de concreción jurídica para la consecución de un fin predeterminado; esta no significa libertad de elección». En ese orden de ideas, «la Administración no elige libremente una opción determinada, ya que, como poder en todo momento dirigido por el Derecho, debe orientarse según los parámetros establecidos en la ley y en su mandato de actuación, ponderándolos autónomamente en el marco de la habilitación actuada». Recordando, por último, que dichos parámetros no solo están establecidos en la ley, sino que también en la Constitución. «[...] en particular, los derechos fundamentales y los principios de proporcionalidad y de igualdad [...]». 
La estructura orgánica de cada organismo regulador se rige por su reglamento de organización y funciones, es decir cada organismo regulador tiene su propia organización ${ }^{20}$. Sin embargo, hasta cierto punto presentan una similitud en cuanto a su estructura, que es común a todos, como se verá a continuación:

- Consejo Directivo.

— Órgano de Control Interno.

- Presidencia.

- Gerencia General.

— Tribunal de Solución de Controversias.

- Cuerpos Colegiados.

— Los demás órganos que determine el Consejo Directivo.

\section{PARÁMETROS PARA SER CONSIDERADO COMO REGULADOR Y CARACTERÍSTICAS COMUNES ENTRE LOS ORGANISMOS REGULADORES SUDAMERICANOS}

Los parámetros de los «entes» considerados como reguladores se pueden establecer tanto en Europa como en Sudamérica, manifestándose de modo uniforme: la especialización técnica en el sector en el cual operan, la deliberación especializada de controversias, la potestad de regulación tarifaria, potestad normativa, su naturaleza jurídica, el tipo de constitución de su órgano decisor, elección del Consejo Directivo, el tiempo de permanencia de sus miembros, el conjunto de potestades y funciones asignadas y, finalmente, su independencia estructural, económica-financiera. Cuando todos ellos se presentan en el «ente», podemos decir que estamos al frente de un organismo regulador ${ }^{21}$.

20 La organización interna de los organismos reguladores peruanos descansa en sus estatutos de organización y funcionamiento. Para OSIPTEL, el Decreto Supremo 104-2010-PCM, aprueba modificación al Reglamento de Organización y Funciones del OSIPTEL, de 3 de diciembre de 2010. Para OSINERGMIN, la Resolución de Consejo Directivo OSINERG 459-2005-OS-CD, de 20 diciembre de 2005 y sus modificatorias. Para OSITRAN, el Decreto Supremo 044-2006-PCM, de 24 de julio de 2006. Para SUNASS, el Decreto Supremo 017-2001-PCM, de 21 de febrero de 2001.

21 Vírgala (2011b: 5-13); Valencia, (2004: 407-409); Hernández-Mendible (2009: 167-176). 


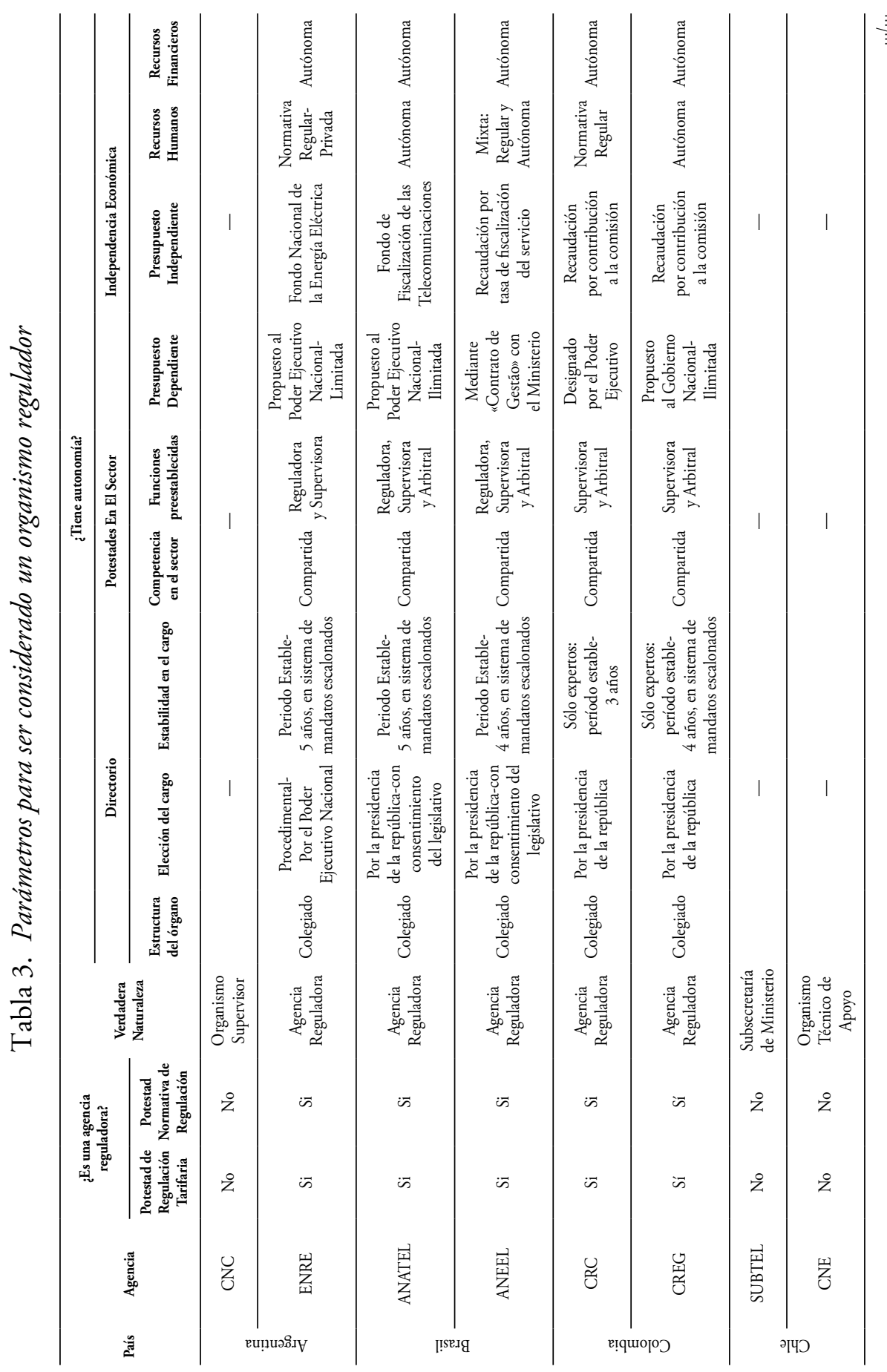




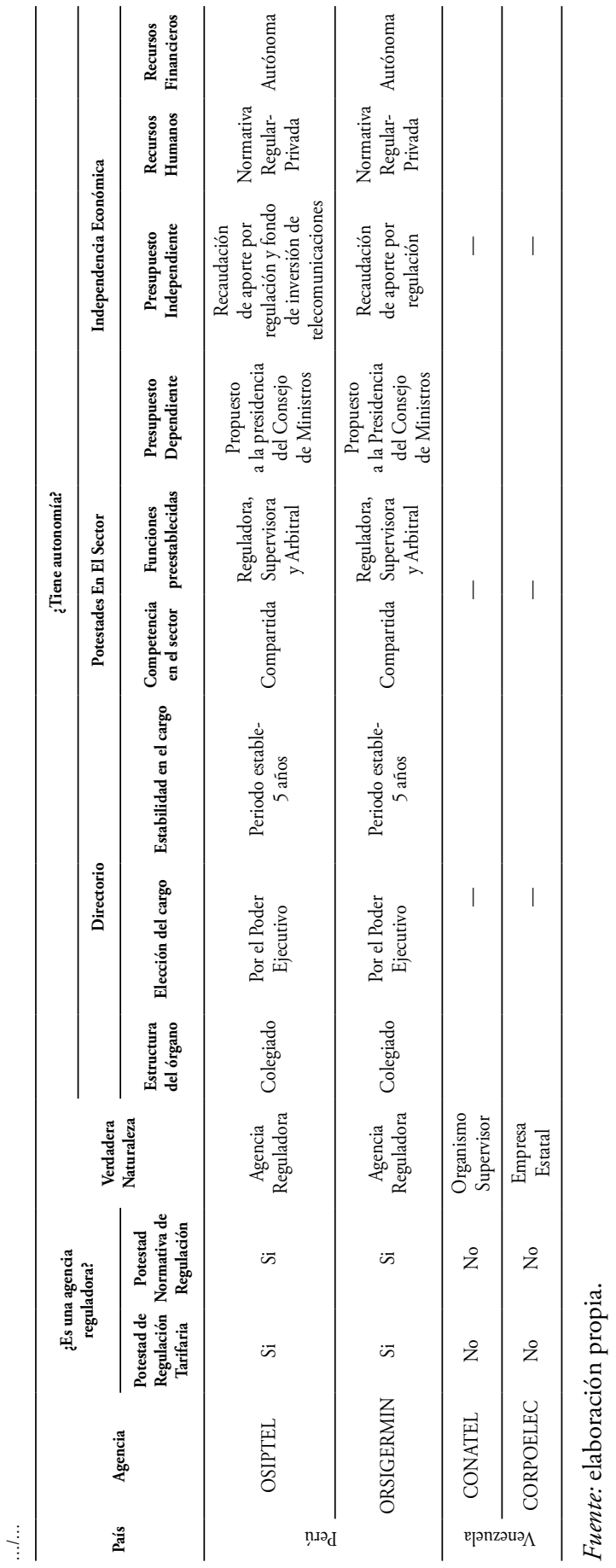




\section{SIMILITUDES ENTRE LOS ORGANISMOS REGULADORES}

Una mayoría significativa de los organismos reguladores sudamericanos presentan similitudes estructurales, toda vez que la mayoría de los entes estudiados conforman una estructura piramidal en su organización, un colegiado como órgano de dirección, que posee un número impar de directores; del mismo modo presentan un periodo análogo de mandato, régimen de cese y de incompatibilidades y, finalmente, admiten la posibilidad de reelección de los directores.

Tabla 4. Relación de los organismos reguladores, número de directores, periodo de mandato, posibilidades de reelección

\begin{tabular}{|c|c|c|c|c|}
\hline País & Organismos Reguladores & $\begin{array}{c}\mathrm{N} .^{\circ} \\
\text { directores }\end{array}$ & Período de mandato & Reelección \\
\hline \multirow{4}{*}{ 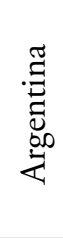 } & ENACOM antigua & & & 1 solo \\
\hline & Comisión Nacional de & 8 & 5 años & período \\
\hline & Comunicaciones (CNC) & & & adicional \\
\hline & $\begin{array}{l}\text { Ente Nacional Regulador } \\
\text { de la Electricidad (ENRE) }\end{array}$ & 5 & 5 años & Sí \\
\hline \multirow{2}{*}{ 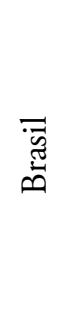 } & $\begin{array}{l}\text { Agencia Nacional de } \\
\text { Telecomunicaciones } \\
\text { (ANATEL) }\end{array}$ & 5 & 5 ańos & $\begin{array}{c}\text { No (no } \\
\text { menciona, } \\
\text { no se puede) }\end{array}$ \\
\hline & $\begin{array}{l}\text { Agencia Nacional } \\
\text { de Energía Eléctrica } \\
\text { (ANEEL) }\end{array}$ & 5 & $\begin{array}{c}4 \text { años (2 } \\
\text { directores) y } 3 \text { años } \\
\text { (director general y } \\
\text { dos directores) }\end{array}$ & $\begin{array}{c}\text { No (no } \\
\text { menciona, } \\
\text { no se puede) }\end{array}$ \\
\hline \multirow{2}{*}{$\frac{. \frac{\pi}{0}}{\frac{0}{0}}$} & $\begin{array}{l}\text { Comisión de Regulación } \\
\text { de las Comunicaciones } \\
\text { (CRC) }\end{array}$ & 5 & $\begin{array}{c}3 \text { años (3 } \\
\text { comisionados), } \\
\text { otros } 2 \text { por } \\
\text { exclusiva confianza }\end{array}$ & $\begin{array}{c}\text { No (no } \\
\text { menciona, } \\
\text { no se puede) }\end{array}$ \\
\hline & $\begin{array}{l}\text { Comisión de Regulación } \\
\text { de Energía Eléctrica y Gas } \\
\text { (CREG) }\end{array}$ & 8 & $\begin{array}{c}4 \text { años ( } 5 \text { expertos), } \\
\text { otros } 3 \text { por } \\
\text { exclusiva confianza }\end{array}$ & Sí (expertos) \\
\hline \multirow{2}{*}{$\frac{\ddot{J}}{0}$} & $\begin{array}{l}\text { Superintendencia de } \\
\text { Telecomunicaciones } \\
\text { (SUBTEL) }\end{array}$ & 1 & Exclusiva confianza & No \\
\hline & $\begin{array}{l}\text { Comisión Nacional de } \\
\text { Energía }(\mathrm{CNE})\end{array}$ & 1 & Exclusiva confianza & No \\
\hline
\end{tabular}




\begin{tabular}{|c|c|c|c|c|}
\hline País & Organismos Reguladores & $\begin{array}{c}\mathrm{N} .^{\circ} \\
\text { directores }\end{array}$ & Período de mandato & Reelección \\
\hline \multirow{2}{*}{ 胥 } & $\begin{array}{l}\text { Organismo Supervisor } \\
\text { de la Inversión Privada } \\
\text { en Telecomunicaciones } \\
\text { (OSIPTEL) }\end{array}$ & 5 & 5 ańos & $\begin{array}{l}1 \text { solo } \\
\text { período } \\
\text { adicional }\end{array}$ \\
\hline & $\begin{array}{l}\text { Organismo Supervisor de } \\
\text { la Inversión en Energía y } \\
\text { Minas (OSINERGMIN) }\end{array}$ & 5 & 5 ańos & $\begin{array}{l}1 \text { solo } \\
\text { período } \\
\text { adicional }\end{array}$ \\
\hline \multirow{2}{*}{ 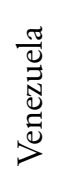 } & $\begin{array}{l}\text { Comisión Nacional de } \\
\text { Telecomunicaciones } \\
\text { (CONATEL) }\end{array}$ & 5 & $\begin{array}{l}\text { Libre } \\
\text { nombramiento y } \\
\text { remoción }\end{array}$ & No \\
\hline & (CORPOLEC) & \multicolumn{3}{|c|}{ SECTOR DE ENERGÍA ESTATIZADO } \\
\hline
\end{tabular}

Fuente: elaboración propia.

\section{CONTROLES SOBRE LOS ORGANISMOS REGULADORES SUDAMERICANOS}

La independencia relativa que se debe otorgar a los organismos reguladores debe ser suficiente para que su actividad se realice eficazmente, sin injerencia de los poderes políticos o de los operadores predominantes en los mercados. Sin embargo, ello no quiere decir que estos organismos no puedan ser objeto de control por órganos legítimamente autorizados para ello. Es posible afirmar junto a Schmidt-Assmann ${ }^{22}$, que «la autonomía o independencia de la Administración se debe corresponder con un sistema de controles administrativos adecuado a aquella». De similar postura es el profesor Scheuner (citado por Schmidt-Assmann), al sostener que «la responsabilidad y el control constituyen dos elementos esenciales de todo ordenamiento constitucional democrático».

Por su parte, es importante establecer mecanismos de control por parte de la comunidad de usuarios, generando los medios de transparencia, como publicidad de los procesos y procedimientos, acceso directo a los expedientes administrativos, publicación y difusión de sus resoluciones administrativas en sus portales web, entre otros. Sin embargo, considero que ello no basta en lo que concierne al control al cual está sujeta toda actividad administrativa en un

22 Schmidt-Assmann (2003: 225). 
Estado de Derecho, sino que, no obstante ser necesaria su independencia para actuar, se debe establecer un equilibrio entre el control que se dan a sus actividades y la discrecionalidad independiente.

A continuación, una clasificación de los diferentes controles existentes, sin perjuicio de que puedan existir otros mecanismos en los ordenamientos jurídicos sudamericanos, según el órgano que se encuentre facultado para ello ${ }^{23}$ :

\section{EL CONTROL PARLAMENTARIO}

El Parlamento, en un Estado de derecho, tiene la función de fiscalizar al Gobierno y a las Administraciones públicas realizando un control político sobre sus actividades. Así se desprende de lo expuesto en el art. 97 de la Constitución Política del Perú ${ }^{24}$. No obstante, los mecanismos de control más conocidos y estudiados son aquellos que recaen sobre los ministros y demás funcionarios con cargos políticos, como son la interpelación o la censura. La fiscalización del Parlamento recae sobre todos los organismos públicos, pero en el caso de los organismos reguladores normalmente llega de manera atenuada y con la finalidad de solicitar informes, investigar o conocer la situación del sector que se está regulando (Abruña, 2010: 140-141) 25 .

$\mathrm{Al}$ respecto, el profesor Rubio Correa destaca que la comisión parlamentaria de investigación podría levantar el secreto bancario y la reserva tributaria, entre otras medidas, pero con la única excepción de que no afecte a la intimidad personal, pues este derecho está protegido en el art. 2 inciso 5 de la Constitución Política del Perú ${ }^{26}$.

23 Hernández-Mendibile (2009: 215-221).

24 «El Congreso puede iniciar investigaciones sobre cualquier asunto de interés público. Es obligatorio comparecer, por requerimiento, ante las Comisiones encargadas de tales investigaciones, bajo los mismos apremios que se observan en el procedimiento judicial». Para el cumplimiento de sus fines, dichas comisiones pueden acceder a cualquier información, la cual puede implicar el levantamiento del secreto bancario y el de la reserva tributaria; excepto la información que afecte la intimidad personal. Sus conclusiones no obligan a los órganos jurisdiccionales.

25 Para mayor profundidad, el aún Proyecto de Ley 2466/2012-CR, que obliga a que los organismos reguladores informen anualmente al Congreso de la República sobre el cumplimiento de sus funciones, de 16 de julio de 2013, cuyo art. único obliga a los presidentes del Consejo Directivo o jefes institucionales de los organismos reguladores (OSIPTEL, OSINERGMIN, OSITRAN, SUNASS) a informar sobre las funciones asignadas a su cargo. Ver expediente digital: http://bit.ly/34iyN1d.

26 Rubio (2012:177). 
En concreto, acerca de estos mecanismos de control en el Perú, podemos mencionar los siguientes.

\subsection{Procedimientos de investigación por parte del Parlamento}

El Parlamento, como órgano que representa y dirige los intereses de la nación, no solo puede realizar investigaciones sobre acusaciones constitucionales a parlamentarios, ministros, expresidentes u otros funcionarios en cargo o que ya lo hayan dejado. En el caso peruano, de acuerdo al art. 87 del Reglamento del Congreso de la República, tiene legítimo interés en analizar cualquier asunto de interés público ${ }^{27}$. En este sentido, las investigaciones que realice el Parlamento deben respetar el debido proceso, estableciéndose una comisión estable para ello y que culmine en la formulación de propuestas de solución a los problemas, proyectos de ley, recomendaciones a los organismos públicos, etc.

Por ello, los miembros del órgano directivo del organismo regulador, como funcionarios a cargo de dicha entidad, están sujetos a ser invitados a dicha comisión de investigación y tienen la obligación de comparecer ante esta, a ser interrogados mediante cuestionarios pertinentes a temas de su competencia y a brindar la información que necesite dicha Comisión para esclarecer los hechos bajo investigación. En estos casos, previa autorización del pleno del Parlamento, cabría la posibilidad de levantar la reserva de la información antes descrita. Sin embargo, solo cabe la posibilidad de brindarla a la comisión para efectos de la investigación, en sesiones reservadas, y cabría responsabilidad para los miembros de esta si algún documento es filtrado indebidamente.

Un punto de mención aparte consiste en que la comisión investigadora se establezca con el objeto de hacer comparecer a uno de los miembros de un órgano directivo de un organismo regulador en calidad de investigado. las investigaciones que realicen estas comisiones pueden establecerse en relación a que uno de estos funcionarios haya realizado, presuntamente, un delito o una infracción laboral en el ejercicio de sus funciones. Sin embargo, al no estar bajo inmunidad alguna, no se debe entender como una fase prejudicial, sino como una investigación distinta, de carácter político. Esta solo puede terminar con unas conclusiones aparentes sobre la responsabilidad del funcionario, remitiendo

27 Cualquier congresista puede pedir a los ministros, al Jurado Nacional de Elecciones, al Contralor General, al Banco Central de Reserva, a la Superintendencia de Banca y Seguros, a los Gobiernos regionales y locales y a todos los demás organismos del sector público, los informes que estime necesarios para el ejercicio de su función. Ver el texto íntegro del reglamento en: http://bit.ly/2ouclTo. 
todo lo actuado al Ministerio Público si del informe, que debe ser aprobado en pleno, se deduce que el delito ha de imputársele al funcionario.

Sin embargo, de dicha investigación política, se debe dejar de lado la posibilidad de que se puedan aplicar sanciones como la del despido o separación de sus funciones al funcionario, esto es, que es oportuno no establecer, como motivo de cese de funciones de un directivo del organismo regulador, un informe desfavorable de una comisión de investigación del Parlamento. Por el contrario, una sentencia firme del órgano jurisdiccional competente que imponga una sanción por algún delito sí puede ser un fundamento para separar al directivo de sus funciones; en caso contrario, el Parlamento tendría un control excesivo sobre el órgano directivo del regulador, pudiendo, mediante una cantidad de votos, cesar a sus miembros. En consecuencia, dichas comisiones deben limitarse a recomendar la denuncia respectiva y otorgar al Ministerio Público-Fiscalía de la Nación lo investigado por esta, dando publicidad al caso para que la opinión pública y los usuarios sepan de los sucesos.

\subsection{Solicitud de información al organismo regulador}

Todos los parlamentarios, en ejercicio de sus atribuciones de control político, deben poder solicitar a los miembros del órgano directivo del organismo regulador la información sobre sus actividades, la memoria anual o algún otro instrumento que resuelva dudas sobre el correcto ejercicio de sus funciones. Sin embargo, no cabe la posibilidad de solicitar cualquier documento sin fundamentación alguna o verbalmente. Por el contrario, las solicitudes de información deben contener las causas detalladas que llevan al legislador a pedir la información que necesite. Además, tenemos que excluir cierta información que, de publicarse o de ser de conocimiento de cualquier persona fuera del órgano directivo, ponga en riesgo la actividad regulatoria; por ejemplo, actas de debates que aún no llegan a una decisión y deban estar en reserva, los datos sobre planes de vigilancia que deben ser espontáneos, estadísticas económicas que indebidamente pueden beneficiar a algún operador económico en concreto, etc.

Se reitera, por tanto, que este mecanismo de control político debe estar en equilibro con la independencia que tiene el organismo regulador. Por ello, la solicitud de información no puede entenderse como una orden de un superior jerárquico, sino que este debe ser un método de cooperación con un órgano legitimado democráticamente, para que este último pueda estar en conocimiento de las actividades y últimos detalles sobre el sector regulado para que el parlamentario solicitante pueda proponer algún proyecto de ley en mejora del sector, por ejemplo. 


\section{CONTROL POR PARTE DE LA OPINIÓN PÚBLICA}

\subsection{Control ciudadano}

Finalmente, volvemos a destacar la importancia del control sobre los organismos reguladores ejercido por las asociaciones de usuarios y de los ciudadanos, como usuarios de servicios públicos o titulares de derechos fundamentales que les garantiza una pronta prestación de calidad ${ }^{28}$. En estos casos, existen dos maneras por las cuales se puede ejercer una vigilancia y control ciudadanos sobre estos organismos: uno, a partir de los mecanismos generales de transparencia y control de la Administración pública; y otro a partir de los mecanismos especiales establecidos en la ley de creación del organismo regulador o de la ley general de sector regulado.

En el primer caso, es necesario referirnos a las leyes de control y participación ciudadana sobre la Administración pública en general, puesto que este será el primer medio por el cual los usuarios podrán solicitar la información pública que necesiten y fiscalizar particularmente la actuación del regulador. Sin embargo, es necesario que las formalidades, para este caso de alto interés general, de las solicitudes de información y de orientación se flexibilicen para poder ejercer el control ciudadano de una manera más rápida y eficiente.

En el segundo caso, las leyes especiales de la materia deben prever no solo el control directo de los usuarios sobre el regulador, sino la participación de estos dentro del organismo. De esta manera, es de vital importancia constituir una asociación o consejo de usuarios, institucionalizado conforme a una ley, la del propio organismo regulador, que le otorgue las funciones de fiscalización popular en representación de todos los usuarios, puesto que es más ventajosa la existencia de tal asociación de manera permanente al tener una vigilancia continua que el usuario común no podría hacer. Además, es necesario que su conformación orgánica y sus representantes tengan una estructura similar al del órgano directivo del organismo regulador buscando su independencia.

28 Una de las más emblemáticas asociaciones de consumidores es la Asociación Peruana de Consumidores (ASPEC), una persona jurídica civil sin fines de lucro, gestada por un grupo de consumidores y usuarios en 1994. Su único objetivo de defender los derechos de sus asociados y de quiénes acuden en busca de sus servicios. ASPEC actúa en diversos campos, tales como alimentación, salud, servicios públicos, transporte, educación, productos y servicios en general, entre otros. Ver su web site: http://www. aspec.org.pe/. 


\subsection{Control por parte de los medios de prensa}

En los diversos países sudamericanos donde están implantados los organismos reguladores, el papel de los medios de comunicación especializados, tanto de prensa escrita como televisada, es fundamental, pues sirven como mecanismo de supervisión y fiscalización sobre la actuación de los reguladores, tanto a nivel interno como externo. Constituyen un aparato de presión y de formación de opinión ante la ciudadanía.

\section{CONTROL JUDICIAL}

\subsection{Impugnación en sede contencioso-administrativa}

En el Perú, toda resolución de instancia administrativa está sujeta a impugnación en sede judicial. Dicha impugnación abriría un proceso contencioso-administrativo a causa de que presuntamente se haya vulnerado algún derecho del administrado (Priori, 2007:67) ${ }^{29}$.

Esto es lo que sucedería con las decisiones de los organismos reguladores que afecten los derechos de algún administrado, permitiendo a este ejercer su derecho a plantear una acción contenciosa-administrativa con el objetivo de acceder a la tutela efectiva de sus derechos ante el órgano jurisdiccional correspondiente. De esta forma los actos administrativos, mediante los cuales el organismo regulador fije o apruebe las tarifas correspondientes a la prestación del servicio, pueden ser impugnados en vía judicial. También lo son las resoluciones que busquen poner fin a incertidumbres jurídicas o a conflictos entre operadores del mercado, dictadas por el tribunal administrativo del regulador ${ }^{30}$.

29 Respecto a la finalidad del proceso contencioso-administrativo, nos remitimos a lo señalado por el autor citado, extrayendo los siguientes fundamentos: «1. El Estado constitucional y el principio de constitucionalidad pues en dicho modelo se concibe que la Administración, la jurisdicción y los ciudadanos se encuentran sometidos, aunque de diversa forma, a la ley y en última instancia a la Constitución. 2. Los derechos fundamentales, pues cualquier acto derivado del Estado que pretenda vulnerarlos supondrá un acto que afecta principios básicos de la colectividad. 3. La necesidad de control entre los diversos órganos del Estado ya que el proceso contencioso permite el control interorgánico entre los diversos detentadores de poder de la gestión estatal y, 4. El derecho a la tutela jurisdiccional efectiva en la medida que existe la necesidad que el Estado garantice a los particulares, el acceder a los órganos jurisdiccionales para que se tutelen sus derechos frente a una actuación administrativa que no se halla conforme a derecho».

30 Que en este caso son el Tribunal de Solución de Controversias (TSC)-OPSITEL, TSC-OSINERGMIN, TSC-OSITRAN y, el Tribunal Administrativo de Solución de Reclamos (TRASR) de SUNASS. 
El control de legalidad que ejercen los órganos jurisdiccionales es compatible y necesario en un Estado de derecho en el cual actúan los organismos reguladores. Se puede debatir, entonces, qué órgano jurisdiccional debe ser competente para revisar los actos de los reguladores, no estableciéndose diferencia alguna con los demás actos administrativos o previendo un tratamiento especial designando un órgano de mayor jerarquía dentro del Poder Judicial. La intervención de los órganos jurisdiccionales no se limitará a un simple control jurídico que anulará lo dispuesto por el regulador, sino que, al tutelar efectivamente los derechos del administrado, dispondrá de medidas de obligatorio complimiento para el regulador para que el administrado ejerza sus derechos ${ }^{31}$.

Es decir, el órgano jurisdiccional puede sustituir el acto administrativo por una decisión suya, de tal manera que este termine actuando como organismo regulador, aparte de que en materia cuasi jurisdiccional el órgano jurisdiccional puede suplir por decisión propia la solución que considere realmente jurídica y conveniente en tutela efectiva de los derechos de uno de los administrados.

Sobre la problemática que esta tutela judicial plantea,

[...] el Poder Judicial asume, pues, crecientemente un papel que no le corresponde y las decisiones sociales se sitúan en un locus inidóneo, con la consecuente distorsión del orden de responsabilidades y apoderamientos de decisión establecido por la Constitución [...]. Esta dinámica lleva a este (el juez) a tener no solo que corregir las infracciones del orden jurídico del Poder Ejecutivo, sino que pronunciarse, decir positivamente -incluso en sustitución de dicho poder- la solución procedente en el caso ${ }^{32}$.

Por tanto, debe tenerse en cuenta de que, si se dan los últimos supuestos, se debe establecer como requisito indispensable de dicha decisión jurisdiccional, el asesoramiento técnico externo e independiente (de los intereses económicos en juego), para que el órgano pueda tomar una decisión jurídicamente correcta; $y$, al estar la independencia del regulador en juego, se crea necesario que la revisión de sus decisiones debe recibir un tratamiento especial. Esto es, el órgano jurisdiccional encargado de revisar las decisiones del regulador, en ejercicio de sus actividades más importantes, debe ser diferente al normalmente establecido para la revisión de la actividad administrativa y establecerse en las normas referidas al proceso contencioso-administrativo un órgano de

31 Egúsquiza (2010: 10-12).

32 Parejo (2008: 122-127). 
mayor jerarquía para ello, previéndose, asimismo, quién debe tomar una decisión final ante los casos de apelación u otros recursos impugnatorios ${ }^{33}$. Tal es el caso de la implementación en el Poder Judicial peruano, de los juzgados contencioso-administrativos con subespecialidad en temas de mercado ${ }^{34}$, que revisan las actuaciones de los organismos reguladores que constituyen cosa decidida en sede administrativa.

Como se ha de advertir, el tópico de los controles sobre los organismos reguladores pone en tela de juicio la vigencia normativa del principio de separación de poderes dentro de un Estado social de derecho, en especial debido a que el Poder Judicial, ya sea por la vía del proceso contencioso-administrativo o el proceso constitucional de amparo, exige la defensa de los derechos fundamentales de los usuarios y las empresas. Sin embargo, ello podría incidir negativamente en la eficacia, independencia y razón de ser de, entre otros casos, los organismos reguladores, teniendo en cuenta que, si se siguen aplicando la tutela impugnatoria de sus actos administrativos sin modificación alguna, los órganos constitucionales se convertirían en órganos reguladores ad hoc, siendo ello inaceptable.

\subsection{Garantías constitucionales}

El proceso contencioso-administrativo no sería la única vía para conocer de actos administrativos del organismo regulador, sino que, como muchos

33 Negreto (2009: 216-218).

34 Véase la Resolución Administrativa 111-2013-CE-PJ, de fecha 14 de junio de 2013, por el cual se concibe la necesidad de contar con un ente imparcial y altamente cualificado en su especialización, estableciendo Salas y Juzgados Contencioso Administrativos con Subespecialidad Tributaria, Aduanera y de Mercado. El año 2016 se termina de consolidar el sistema de revisión judicial de los temas regulatorios, modificándose la denominación y ampliándose la competencia funcional de diversos órganos jurisdiccionales de la Corte Superior de Justicia de Lima, a través de la Resolución Administrativa 159-2016-CE-PJ, de fecha 22 de junio de 2016, que dispone la creación de Salas y Juzgados Contencioso Administrativos con Subespecialidad en Temas de Mercado, que asuman dentro del ámbito de su competencia, el trámite de los procesos contenciosos administrativos donde sean parte los organismos públicos reguladores como el Organismo Supervisor de la Inversión Privada en Telecomunicaciones (OSIPTEL), el Organismo Supervisor de la Inversión en Energía y Minería (OSINERGMIN), el Organismo Supervisor de la Inversión en Infraestructura de Transporte de Uso Público (OSITRAN) y la Superintendencia Nacional de Servicios de Saneamiento (SUNASS); así como aquellos procesos contenciosos administrativos donde sean parte el Organismo Supervisor de las Contrataciones del Estado (OSCE) y la Superintendencia Nacional de Salud (SUSALUD). 
ordenamientos sudamericanos han previsto, se tienen a disposición de los administrados las garantías constitucionales. Se debe tener en cuenta la posibilidad de recurrir a la acción de garantía constitucional de amparo. Por ejemplo, en el caso argentino ${ }^{35}$ se podría interponer amparo ante los actos de un organismo regulador que no se correspondan con el fomento de la libre competencia, afectando el interés del administrado como operador económico débil en el mercado. Sin embargo, se debe tener en cuenta si la vía judicial del contencioso-administrativo puede suplirla; en el supuesto citado, dependería del juez constitucional analizar el caso o no, estableciendo que se ha restringido concretamente un derecho fundamental, siendo la vía de la jurisdicción constitucional más idónea que la del contencioso administrativo, aunque también puede observarse una extrapolación que debe ser mejor regulada por el ordenamiento ${ }^{36}$.

Sin embargo, no habría problema para ejercer acción de garantía constitucional (como el amparo ${ }^{37}$ o el habeas data $a^{38}$, en el Perú), en el caso de que el organismo regulador se niegue a otorgarle la información referida a esta, siempre y cuando no se encuentre una vía diferente como la establecida para el caso de que un ciudadano solicite información más general al regulador.

35 El art. 43 de la Constitución de la Nación Argentina, señala: «Toda persona puede interponer acción expedita y rápida de amparo, siempre que no exista otro medio judicial más idóneo, contra todo acto u omisión de autoridades públicas o de particulares, que en forma actual o inminente lesione, restrinja, altere o amenace, con arbitrariedad o ilegalidad manifiesta, derechos y garantías reconocidos por esta Constitución, un tratado o una ley. En el caso, el juez podrá declarar la inconstitucionalidad de la norma en que se funde el acto u omisión lesiva. Podrán interponer esta acción contra cualquier forma de discriminación y en lo relativo a los derechos que protegen al ambiente, a la competencia, al usuario y al consumidor, así como a los derechos de incidencia colectiva en general, el afectado, el Defensor del Pueblo y las asociaciones que propendan a esos fines, registradas conforme a la ley, la que determinará los requisitos y formas de su organización. Toda persona podrá interponer esta acción para tomar conocimiento de los datos a ella referidos y de su finalidad, que consten en registros o bancos de datos públicos, o los privados destinados a proveer informes, y en caso de falsedad o discriminación, para exigir la supresión, rectificación, confidencialidad o actualización de aquéllos. No podrá afectarse el secreto de las fuentes de información periodística».

36 Gordillo (2003: 15).

37 Ver apartado 2 del art. 200 de la CPP.

38 Ver apartado 3 del art. 200 de la CPP. 


\section{CONTROL POR PARTE DEL GOBIERNO}

Podría decirse que el Gobierno ejerce un débil control sobre los reguladores, mediante la aplicación de la Ley 27785, Orgánica del Sistema Nacional de Control y de la Contraloría General de la República (LOSNC-CGR), de 23 de julio de 2002 y sus modificatorias, que en su art. 2 señala ${ }^{39}$ :

Es objeto de la Ley propender al apropiado, oportuno y efectivo ejercicio del control gubernamental, para prevenir y verificar, mediante la aplicación de principios, sistemas y procedimientos técnicos, la correcta, eficiente y transparente utilización y gestión de los recursos y bienes del Estado, el desarrollo honesto y probo de las funciones y actos de las autoridades, funcionarios y servidores públicos, así como el cumplimiento de metas y resultados obtenidos por las instituciones sujetas a control, con la finalidad de contribuir y orientar el mejoramiento de sus actividades y servicios en beneficio de la Nación.

Cabe mencionar que toda la Administración pública no escapa del actuar de una instancia del Ejecutivo, me refiero al Ministerio de Economía y Finanzas en materia presupuestaria que se asigna a los reguladores y a la Contraloría General de la República. Se ha tratado de justificar su actuación de modo constitucional, como diría Rubio Correa: «[...] para que los recursos del Estado se utilicen adecuadamente y honestamente $[\ldots] \|^{40}$. Sin embargo, no se puede negar que, a veces y ciertamente, este sometimiento constituye un ligero obstáculo para ejecutar su propio presupuesto asignado, no solo el presupuesto transferido por el Gobierno central sino el suyo propio producto de su recaudación ${ }^{41}$. De este modo, al observar las Directivas expedidas por Contraloría, se somete a rigurosos procedimientos estatales cuyos plazos establecidos —al igual que sus mecanismos - son un poco lentos.

39 Para contrastar lo manifestado ver el Texto integrado de la Ley Orgánica de la Contraloría (TILOC), alojado en el siguiente sitio web de este órgano constitucionalmente autónomo: http://bit.ly/2MZpxsT.

40 Rubio (2012: 153,154).

41 Una cierta crítica al sistema ya planteado es lo señalado por Bonifaz, el mismo que puede verse en el diario Gestión: http://bit.ly/2BXOgaA. Esto es coherente con el fortalecimiento de su autonomía, considerando que el objetivo específico 6 del Plan Bicentenario, marco institucional y jurídico que garantiza la seguridad de las inversiones, numeral b) Acciones estratégicas fortalecer la autonomía y las capacidades técnicas de los organismos reguladores para su actuación independiente. Ver http:// www.ceplan.gob.pe/plan-bicentenario. 
Del mismo modo, el art. 3 de la LOSNC-CGR habilita la observancia y cumplimiento de los organismos reguladores al ámbito de aplicación de la Contraloría General de la República, en el modo siguiente:

Las normas contenidas en la presente Ley y aquellas que emita la Contraloría General son aplicables a todas las entidades sujetas a control por el Sistema, independientemente del régimen legal o fuente de financiamiento bajo el cual operen. Dichas entidades sujetas a control por el Sistema, que en adelante se designan con el nombre genérico de entidades, son las siguientes ${ }^{42}:$ «[..] letra e) Los Organismos reguladores de los servicios públicos y las entidades a cargo de supervisar el cumplimiento de los compromisos de inversión provenientes de contratos de privatización».

Asimismo, el art. 5 de la LOSNC establece la especialidad de esta norma, la misma que prevalece sobre cualquier norma general: "Las disposiciones de esta Ley, y aquellas que expide la Contraloría General en uso de sus atribuciones como ente técnico rector del Sistema, prevalecen en materia de control gubernamental sobre las que, en oposición o menoscabo de estas, puedan dictarse por las entidades".

Del mismo modo, existe un número significativo de resoluciones de Contraloría, así como directivas en la que se aprueban lineamientos de política en materia de control para los organismos reguladores. Uno de ellos, por citarlo, descansa en la Directiva 018-2013-CG/PEC, de 22 de enero de 2014, en el $2 .^{\circ}$ párrafo, en el punto 2.13; que señala: «En los organismos reguladores se incidirá en la gestión de la entidad, pudiendo cubrir en su alcance la existencia de criterios y procedimientos para la fijación de tarifas, la evaluación de los mecanismos de supervisión en los procesos de fiscalización y sanción impuestos por la prestación irregular de los servicios según las condiciones de riesgo analizados».

Lo mismo sucede con la resolución de Contraloría 440-2013 CG, de 27 de diciembre de 2013, en la que se dispone la aprobación de los planes de control de las oficinas de control interno, y que por cierto tienen una imbricación

42 «La Contraloría General de la República, de acuerdo a la CPP, es una entidad descentralizada de Derecho Público que goza de autonomía conforme a su ley orgánica. Es el órgano superior del Sistema Nacional de Control. Supervisa la legalidad de la ejecución del Presupuesto del Estado, de las operaciones de la deuda pública y de los actos de las instituciones sujetas a control. El Contralor General es designado por el Congreso a propuesta del Poder Ejecutivo, por siete años. Puede ser remover por el Congreso por falta grave» (ver art. 82 del CPP). 
dentro de la estructura de los organismos reguladores para fiscalizar a la propia entidad regulatoria; pueden verse los anexos de la mencionada resolución ${ }^{43}$.

Considero que la Contraloría General de la República tiene una cierta relevancia en temas de ejecución presupuestaria, pues tiende a regular, fiscalizar, controlar y sancionar (en caso de que se encuentren hallazgos) por lo ejecutado por los organismos reguladores. También ejerce presión el Ministerio de Economía y Finanzas cada vez que se expresa con sus opiniones, directivas, apoyo técnico y, hasta hace poco, promoción en los proyectos de ley en el Congreso de la República, para apartar a los organismos reguladores del diseño y renegociación de los contratos de concesión de infraestructura con empresas privadas. Y me refiero, concretamente, al proyecto por el cual se limita la participación de los organismos reguladores en dicha supervisión ${ }^{44}$.

\section{CONCLUSIONES}

Los organismos reguladores europeos y sudamericanos presentan parámetros de independencia del poder público, que pueden reunirse en tres grupos: los de incidencia organizativa, los de incidencia funcional y, en función de la materialización de las dos primeras, los parámetros con incidencia económica o financiera. Sin embargo, es pertinente acotar que éstos no se limitan a fortalecer la independencia respecto del poder público, sino que también son una principal barrera frente a la intromisión de los agentes económicos externos.

Existe una característica común entre los organismos reguladores europeos y los sudamericanos, que pueden conjugarse como: potestad de regulación tarifaria; potestad normativa; naturaleza jurídica; tipo de constitución de su órgano decisor; elección del Consejo Directivo, su permanencia en el cargo; conjunto de potestades y funciones asignadas; $y$, finalmente, su independencia económica-financiera.

Los organismos reguladores en el Perú se rigen por los siguientes controles: a) parlamentario, en uso de sus atribuciones de control político emanado de la Constitución; b) ciudadano, a partir de las acciones promovidas por el propio ente regulador, como audiencias públicas para aprobación de normas,

43 Ver los anexos que recaen en los números: 288 para el caso de OSIPTEL; 289 para el caso de OSINERGMIN; así como 290 OSITRAN, ver enlace: http://bit.ly/2qPOuhI.

44 En la mayoría de las ocasiones al PROINVERSIÓN, brazo derecho del MEF, se le concede en la práctica facultades regulatorias y, como seńala Távara (2014), invade el ámbito especializado de los reguladores. Ver la crítica a dicha medida en su momento: http://bit.ly/2N1dknm. 
publicidad de sus procedimientos, sin espacio para asociaciones de usuarios de servicios públicos que vigilen la buena marcha de los mismos y ejerzan actos de fiscalización en forma directa; c) judicial y constitucional, a través de demandas contencioso administrativas o procesos constitucionales, en los que se efectiviza la tutela de derechos de los usuarios de estos servicios públicos regulados, y d) gubernamental, a través de la Contraloría General de la República y el Sistema Nacional de Control.

La mayor independencia de los organismos reguladores en el Perú debe fortalecerse en el ámbito funcional, a través de una menor injerencia de la Administración central en las decisiones sobre su organización, presupuesto, designación de funcionarios, debiendo limitarse a la elaboración de las políticas públicas generales en torno al sector regulado o de este como parte de un plan macro - por ejemplo-, de prestaciones de servicio público de modo que no afecte su grado de independencia.

Un aspecto fundamental a modificar en la legislación vinculada a los organismos reguladores peruanos, que garantice la independencia relativa de sus funcionarios, debe radicar en que el personal de confianza sea determinado por ley, pues la legislación que regula el servicio civil -Autoridad Nacional del Servicio Civil (SERVIR) — se encuentra dispersa y aún no debidamente reglamentada, estableciendo varios regímenes privados aplicables. En ese sentido, es necesario que la ley de contratación laboral para los organismos reguladores sea una ley general estable que permita la especialización técnica en el ascenso de su personal y de acuerdo a una línea de carrera que permita el incentivo en base a la meritocracia.

La independencia de los organismos reguladores en el Perú debería constituir parte del derecho a una buena administración, principio por el cual cada sociedad dentro de un Estado social de derecho, permite que, a través de estos entes, el ciudadano pueda participar en las actuaciones administrativas en las que éstos tengan un legítimo interés. Resulta indispensable la existencia de una junta de usuarios que fiscalice las actuaciones de los organismos reguladores que permita ejercer un control mayor de parte de la sociedad, a fin de cautelar que este cumpla con su función primordial de protección del interés general y de los derechos fundamentales del ciudadano.

\section{Bibliografía}

Abruña, A. (2010). Delimitación jurídica de la Administración pública en el ordenamiento peruano. Lima: Palestra Editores.

Betancor, A. (2010). Regulación: mito y derecho. Desmontando el mito para controlar la intervención de los reguladores económicos. Pamplona: Editorial Thomson Reuters-Civitas.

Cassagne, J. C. (2010). Derecho Administrativo. Lima: Palestra Editores. 
Egúsquiza, M. L. (2010). Análisis de los pronunciamientos judiciales emitidos en procesos contencioso administrativos sobre impugnación de resoluciones de las instancias de solución de controversias. Lima: OSIPTEL, Tribunal de Solución de Controversias. Disponible en: http://bit.ly/2BT6vOn.

Garrido, F. (2002). Tratado de Derecho Administrativo. Volumen II. Parte general: Conclusión. Madrid: Editorial Tecnos.

Gordillo, A. (2003). Tratado de Derecho Administrativo (Vol. I). Buenos Aires: Editorial Fundación de Derecho Administrativo.

Hernández-Mendible, V. R. (2009). Telecomunicaciones, regulación y competencia. Caracas: Editorial Jurídica Venezolana.

Martí, S. (2006). Las agencias administrativas en Estados Unidos en la encrucijada de poderes. Revista de las Cortes Generales, 67, 97-136.

Montero, J. J. (2014). La actividad administrativa de la regulación: definición y régimen jurídico. Revista digital de Derecho Administrativo, 12, 23-44.

Negretto, G. (2009). Hacia una nueva visión de la separación de poderes en América latina. En El Estado de Derecho: dilemas para América Latina (pp. 183-221). México: Palestra Editores.

Parejo, L. (2008). Crisis y renovación en el derecho público. Lima: Palestra Editores.

Priori, G. (2007). Comentarios a la ley del proceso contencioso administrativo. Lima: ARA Editores.

Rallo, A. (2014). La Comisión Nacional de los Mercados y la Competencia: los reparos de las Instituciones europeas sobre la independencia del regulador. Teoría y realidad constitucional, 34, 193-234. Disponible en: https://doi.org/10.5944/trc.34.2014.14084.

Rubio, M. (2012). Para conocer la constitución de 1993. Lima: Fondo editorial de la PUCP.

Schmidt-Assmann, E. (2003). La teoría general del derecho administrativo como sistema: objeto y fundamentos de la construcción sistemática. Madrid: Marcial Pons.

Távara, J. (2014). MEF regulador. La República, 18-01-2014. Disponible en: http://bit.ly/2N$1 \mathrm{dknm}$.

Valencia, G. (2004). Servicios públicos y organismos reguladores. Actas del Primer Congreso Nacional Peruano de Derecho Administrativo. Lima: Jurista Editores.

Vírgala, E. (2004). La constitución y las comisiones reguladoras de los servicios de red. Madrid: Centro de Estudios Políticos y Constitucionales.

- (2006). Agencias (y Agencias reguladoras) en la Comunidad Europea. Revista de Derecho Constitucional Europeo, 5, 145-212.

- (2011a). Las autoridades administrativas independientes en España: su regulación jurídica. En Ch. Paola e M. Roberto (eds.). Il modello europeo di regolazione. Atti della giornata di studio in memoria di Salvatore Cattaneo (pp. 289-317). Nápoli: Jovene Editore. (2011.b). Las Agencias reguladoras de la Unión Europea. Granada: Editorial Comares.

- (2014). Los organismos reguladores en el estado constitucional del siglo xxi: su independencia (especial referencia al caso español). Fundamentos, 8, 161-211. 